\title{
Editorial
}

Dermatology

\section{The User-Generated Web-Based Dermoscopy Image Archive of the International Dermoscopy Society: A Contribution to E-Learning and Exchange of Knowledge}

\author{
A. Niederkorn ${ }^{\text {a }}$ G. Gabler ${ }^{\text {b }}$ G. Argenziano ${ }^{c}$ J. Muir ${ }^{d}$ I. Zalaudek ${ }^{\text {a }}$ H.P. Soyer ${ }^{\mathrm{e}}$ \\ R. Hofmann-Wellenhof ${ }^{a}$

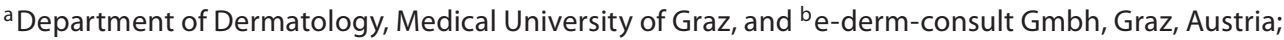

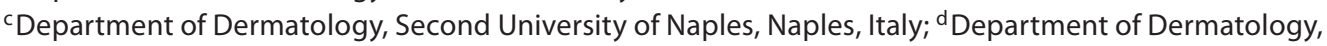 \\ Mater Misericordiae Hospital, and ' Dermatology Research Centre, University of Queensland School of Medicine, \\ Princess Alexandra Hospital, Brisbane, Qld., Australia
}

\section{Key Words}

Image archive $\cdot$ Dermoscopy $\cdot$ Dermatoscopy $\cdot$ Melanoma $\cdot$ E-learning $\cdot$ Internet discussion forum $\cdot$ Teledermatology

\section{Introduction}

Internet databases have become an important source of medical information and have also facilitated the advancement of telemedicine - a modern application to which dermatology is exceptionally well suited $[1,2]$. In recent years, blogs [3,4], online courses and atlases as well as discussion forums in the field of dermoscopy have been established, and these discussion forums in particular are a very useful medium, not only for the exchange of knowledge via the Internet [5], but also for the collection of data for scientific studies [6, 7].

The International Dermoscopy Society (IDS) is an organization which was founded in 2003 to promote clinical research and education in dermoscopy. The society offers free membership, and it currently has more than
4,000 members from over 110 countries who can take part in the online discussion forum on the website www. dermoscopy-ids.org. The members share cases of interest with each other by entering clinical data and images as well as dermoscopic images to an input mask and pose questions pertaining to diagnosis, treatment or dermoscopic features of the lesions. The consultants of the forum then respond to the queries, and in this way all members are able to profit from their knowledge and expertise. Figure 1 depicts a case which was posted on the discussion forum.

Since the website's establishment in 2006, a vast number of cases has been uploaded and discussed, and as such cases with finalized discussions are removed from the discussion forum for clearness of arrangement. Therefore we decided to create a dermoscopy image archive to enable members to locate previous cases based on both clinical and dermoscopic criteria which are entered into an input mask (fig. 2). The arrangement was developed with the goal of offering an additional source of dermoscopic images and expanding the value of the forum as an educational tool in dermoscopy.

\section{KARGER}

Fax +4161306 1234

E-Mail karger@karger.ch

www.karger.com
(C) 2011 S. Karger AG, Basel

$1018-8665 / 11 / 2222-0131 \$ 38.00 / 0$

Accessible online at: www.karger.com/drm
Rainer Hofmann-Wellenhof, MD

Auenbruggerplatz 8

AT-8036 Graz (Austria)

Tel. +433163852371

E-Mail rainer.hofmann@medunigraz.at 


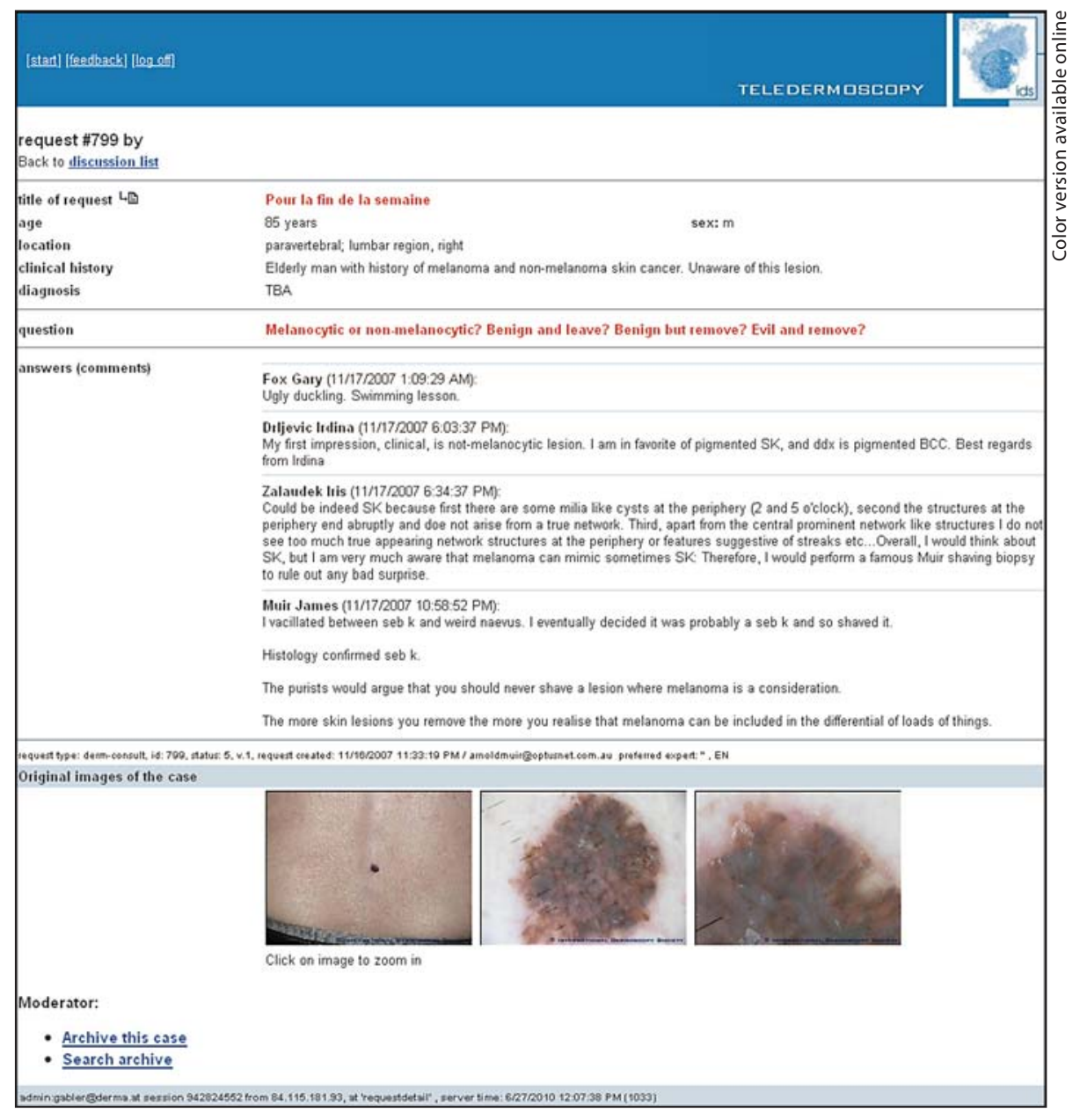

Fig. 1. Example of a case from the online discussion forum posted in 2007 (M.J.).

The outcomes of the first 750 archived cases are presented in this paper in order to paint a clear picture of the use of the discussion forum and the character of lesions frequently present in the web-based dermoscopy image archive.

\section{Methods}

750 cases posted on the discussion forum of the IDS homepage (provided by e-derm-consult, Graz, Austria) between August 2006 and July 2009 were assessed. In order to be added to the image database, each case was required to contain a definite diagnosis, either histopathologically confirmed by the posting author or made in consensus between the discussants. Those cases without definite diagnosis, those with multiple lesions and those discussing non-dermoscopic issues were not archived, neither were cases with low image quality. For approximately 160 cases, the authors were contacted by e-mail and asked to update their requests and post the treatment and diagnosis they had de- cided on to increase the number of cases available for inclusion in this analysis.

An input mask (fig. 1) was created, and specific details including the name of the posting author, the number of comments in the discussion, the location of the lesion and the age of the patient were imported automatically from the discussion forum. Diagnosis, differential diagnoses, malignancy, history and melanocytic/ non-melanocytic differentiation of the lesion, availability of a histopathological diagnosis or a clinical image, skin type and treatment were extracted from the author's specifications on the discussion forum and imported manually. If no information on these criteria was available, the corresponding fields were left empty.

General dermoscopic criteria such as colour, symmetry, pigmentation, global pattern and specific dermoscopic pattern (vascularization dots/globules, network, streaks, blotches, regression structures, pigmentation) [8] were also included in the database. The presence of dermoscopic criteria in the images was partially extracted from the discussion and partially assessed in consensus by the administrators of the IDS archive (R.H.W., A.N.).

Following this, the frequency of the criteria of the 750 archived cases in different subgroups was calculated: benign/malignant lesions, melanocytic/non-melanocytic lesions, melanocytic be- 
nign/malignant lesions, non-melanocytic benign/malignant lesions.

Data on the profession and home countries of the authors and the discussants was extracted from the information they had given during their registration on the IDS homepage.

\section{Results}

In total, 750 requests posted between August 2006 and July 2009 were added to the database. During this period of time, 1,270 requests were posted, but 520 did not meet the criteria of archiving because they had no definite diagnosis (444) or they referred to multiple lesions (49) or non-dermoscopic issues (27).

The 750 archived cases were posted by 85 authors and discussed by 134 members of the IDS discussion forum. The number of comments per post ranged between 1 and 26 with a median of 13 comments for each case.

The authors originated from 25 and the discussants from 34 countries. Australia was named by 16 authors and 33 discussants as their native country. Seven authors were each from Spain and the UK, and 6 came each from Italy, France, Romania and the USA. Many discussants originated from Italy (15), Spain (10), the USA (9) and the UK (8). Most authors were dermatologists (51) or general practitioners (24). The remaining authors declared themselves to be medical doctors (6) or other healthcare professionals (4). The discussants were also mainly dermatologists (79) or general practitioners (35). Nine medical doctors, 4 dermatology residents, 2 surgeons and 5 other healthcare professionals also participated in the discussions.

The archived cases dealt with benign lesions in $65.1 \%$ $(\mathrm{n}=488)$, with malignant lesions in $33.7 \%(\mathrm{n}=253)$ and with indeterminate lesions in $1.2 \%(n=9)$. The diagnoses of three quarters of the cases were histopathologically confirmed: $64.1 \%(n=313)$ of the benign, $95.2 \%(n=241)$ of the malignant and $55.6 \%(n=5)$ of the indeterminate lesions. All 141 malignant melanocytic lesions had diagnoses secured by histopathology. Clinical images were attached to $68.8 \%(n=516)$ of the cases. In $73.6 \%(n=313)$ of all benign, $77.9 \%(n=197)$ of all malignant and $66.7 \%$ $(n=6)$ of all equivocal lesions, a clinical image was available.

Most lesions, 38.8\% ( $\mathrm{n}=291)$, were located on the trunk followed by $15.7 \%(\mathrm{n}=118)$ on the face, $14.8 \%(\mathrm{n}=$ $111)$ on the legs and $10.3 \%(n=77)$ on the arms. The majority of patients, $51.3 \%(\mathrm{n}=385)$, were over 50 years old while $35.7 \%(n=268)$ were aged $25-50$ years. Only $7.2 \%$

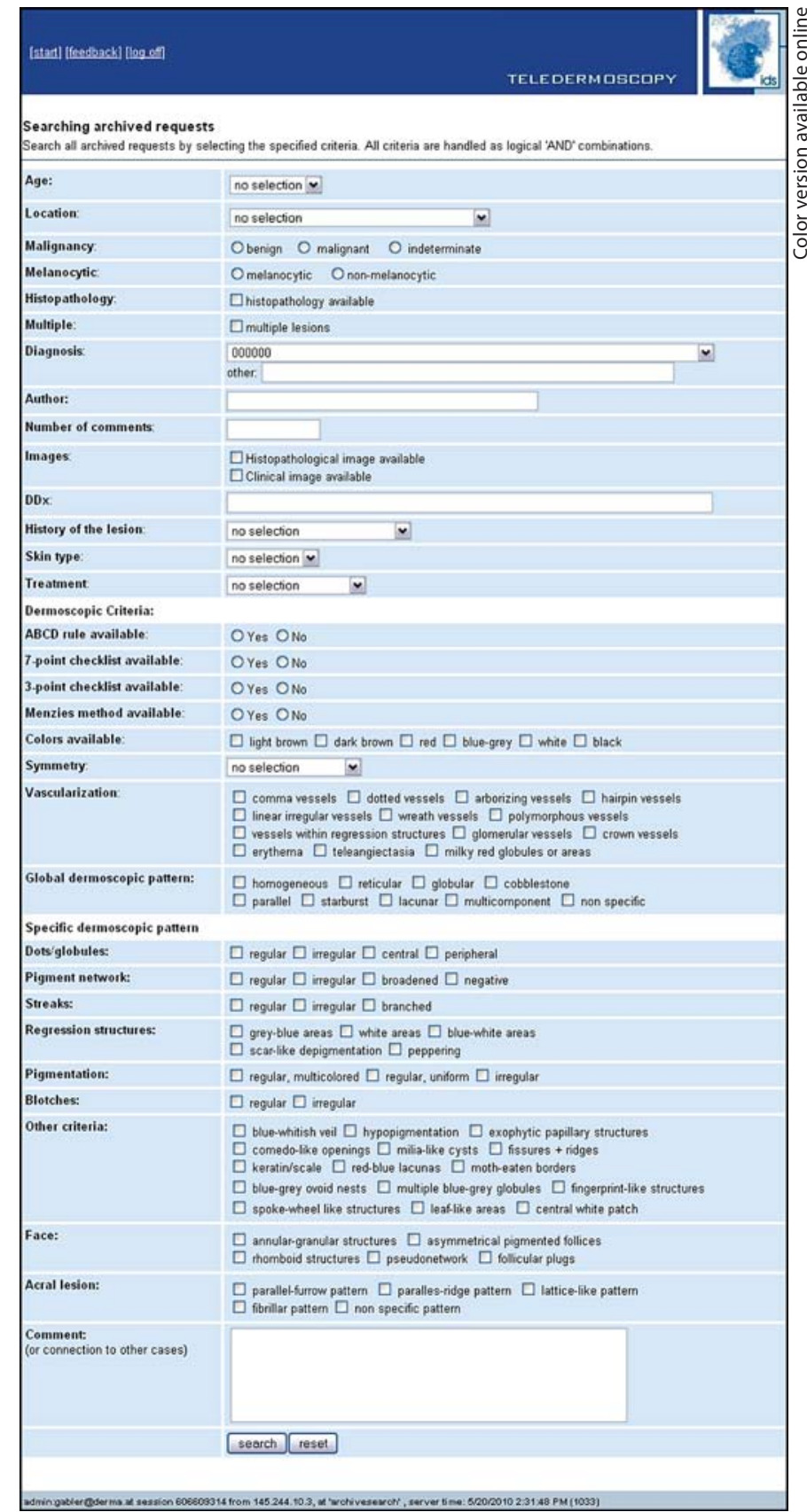

Fig. 2. The search mask of the case archive of the IDS homepage.

( $n=54)$ were aged 15-25 years, and the smallest group was that of patients younger than 15 years with a percentage of $5.7 \%(n=43)$.

A management decision was mentioned by the authors in $78.8 \%(n=591)$ of the archived cases; there was no information on the other lesions. The authors confirmed that excision in toto was performed in $60.2 \%(n=452)$ 
Table 1. Absolute numbers and frequency of diagnosis of the 750 analysed cases

\begin{tabular}{|c|c|c|}
\hline \multirow[t]{2}{*}{ Diagnosis } & \multicolumn{2}{|c|}{ Cases } \\
\hline & $\mathrm{n}$ & $\%$ \\
\hline \multicolumn{3}{|l|}{ Melanocytic lesions } \\
\hline Benign melanocytic naevus & 95 & 12.7 \\
\hline Dysplastic naevus & 86 & 11.5 \\
\hline Melanoma & 60 & 8.0 \\
\hline Superficial spreading & 39 & 5.2 \\
\hline \multicolumn{3}{|l|}{ Melanoma } \\
\hline Acral melanocytic naevus & 30 & 4.0 \\
\hline Spitz/Reed naevus & 29 & 3.8 \\
\hline Congenital melanocytic naevus & 23 & 3.1 \\
\hline Blue naevus & 21 & 2.8 \\
\hline Lentigo maligna (melanoma) & 16 & 2.1 \\
\hline Nodular melanoma & 12 & 1.6 \\
\hline Amelanotic melanoma & 7 & 0.9 \\
\hline Other melanocytic lesions & 5 & 0.7 \\
\hline Acral melanoma & 4 & 0.5 \\
\hline Metastatic melanoma & 3 & 0.4 \\
\hline \multicolumn{3}{|l|}{ Non-melanocytic lesions } \\
\hline Other non-melanocytic lesions & 76 & 10.1 \\
\hline Basal cell carcinoma & 68 & 9.1 \\
\hline Seborrhoeic keratosis & 66 & 8.8 \\
\hline Lentigo & 22 & 2.9 \\
\hline Vascular lesions & 22 & 2.9 \\
\hline Squamous cell carcinoma & 19 & 2.5 \\
\hline Dermatofibroma & 12 & 1.6 \\
\hline Bowen's disease & 11 & 1.5 \\
\hline Parasites & 9 & 1.2 \\
\hline Actinic keratoses & 8 & 1.1 \\
\hline Sebaceous hyperplasia & 5 & 0.7 \\
\hline Paget's disease & 2 & 0.3 \\
\hline
\end{tabular}

and a biopsy in $7.3 \%(\mathrm{n}=55)$. Treatment was not indicated in $6.9 \%(\mathrm{n}=52)$ of cases, and in $4.3 \%(\mathrm{n}=32)$ a follow-up was deemed adequate. An excision was confirmed by the authors for $50.4 \%(n=246)$ of the benign lesions and $79.4 \%(n=201)$ of the malignant lesions.

Table 1 outlines the diagnoses of the archived cases. Melanocytic lesions were discussed in $57.5 \%(n=431)$ of cases, with $65.4 \%(n=282)$ of them being nevi, $32.7 \%$ $(\mathrm{n}=141)$ being melanoma and $1.9 \%(\mathrm{n}=8)$ being indeterminate melanocytic lesions. Non-melanocytic lesions were presented in $42.5 \%(\mathrm{n}=319)$ of the requests, and of these lesions $64.6 \%(n=206)$ were benign, 35.1\% $(n=$ $112)$ were malignant and $0.3 \%(n=1)$ were equivocal. Basal cell carcinomas were the most frequent malignant non-melanocytic lesions, followed by squamous cell carcinomas, Bowen's disease, actinic keratoses and Paget's disease. There were also 3 cases of Merkel cell carcinomas.

Of the investigated lesions, $84.9 \%(n=637)$ were considered asymmetrical in 1 or 2 axes, and $82.9 \%(n=622)$ of all lesions were irregularly pigmented. The presence of dermoscopic criteria in benign or malignant, melanocytic or non-melanocytic lesions is detailed in table 2.

Benign lesions $(\mathrm{n}=488)$ were symmetrical in $21.5 \%$ $(\mathrm{n}=105)$ and showed a regular uniform pigmentation in $10.5 \%(\mathrm{n}=51)$ and a regular multicoloured pigmentation in $13.9 \%(n=68)$, while $75.6 \%(n=369)$ of the benign lesions were irregularly pigmented. The reticular pattern was most common for benign lesions with $41.2 \%$ ( $\mathrm{n}=$ 201 ), followed by the non-specific pattern which was found in $26.4 \%(n=129)$ of the benign lesions.

Asymmetry was found in $97.6 \%(\mathrm{n}=247)$ of the malignant lesions, and the same proportion of malignant lesions showed an irregular pigmentation. The non-specific pattern was observed in $53.0 \%(\mathrm{n}=134)$ of all malignant lesions and the reticular pattern in $26.5 \%(n=67)$.

A starburst pattern was found in $8.2 \%(n=23)$ of the benign melanocytic and $3.5 \%(n=5)$ of the malignant melanocytic lesions but was not evident in any non-melanocytic lesions. Irregular dots/globules, irregular network and grey-blue areas could be found quite frequently in both benign melanocytic and malignant melanocytic lesions. In contrast, regular dots/globules and regular network were very seldom observed in malignant melanocytic lesions.

Of the lesions located on the face $(\mathrm{n}=118)$, annulargranular structures, asymmetrically pigmented follicles and rhomboid structures were predominately found in malignant lesions, while the only criterion seen in a majority of benign lesions was the pseudo-network.

The common pattern of most acral lesions was a parallel furrow pattern followed by the parallel ridge pattern which was the only site-specific acral pattern also found in non-melanocytic lesions. Parallel furrow and fibrillar patterns were found only in benign lesions, whereas parallel ridge, lattice-like and non-specific patterns were also seen in malignant lesions.

\section{Discussion}

This study outlines the successful utilization of an Internet image database of dermoscopic cases created by users for users. The principle may be likened to that of Wikipedia, as all users are able to add supplementary information to the discussion forum on a particular case or 
Table 2. Absolute numbers and frequencies (percentages in parentheses) of dermoscopic criteria found in benign melanocytic, malignant melanocytic, benign non-melanocytic and malignant non-melanocytic lesions

\begin{tabular}{|c|c|c|c|c|}
\hline Dermoscopic criteria & $\begin{array}{l}\text { Naevi } \\
(\mathrm{n}=282)\end{array}$ & $\begin{array}{l}\text { Melanomas } \\
(\mathrm{n}=141)\end{array}$ & $\begin{array}{l}\text { Benign non- } \\
\text { melanocytic } \\
\text { lesions }(n=206)\end{array}$ & $\begin{array}{l}\text { Malignant } \\
\text { non-melanocytic } \\
\text { lesions }(\mathrm{n}=112)\end{array}$ \\
\hline \multicolumn{5}{|l|}{ Symmetry } \\
\hline Symmetrical & $71(25.2)$ & $2(1.4)$ & $34(16.5)$ & $4(3.6)$ \\
\hline Asymmetrical, 2 axes & $164(58.2)$ & $134(95.0)$ & $151(73.3)$ & $106(94.6)$ \\
\hline Asymmetrical, 1 axis & $47(16.7)$ & $5(3.5)$ & $21(10.2)$ & $2(1.8)$ \\
\hline \multicolumn{5}{|l|}{ Pigmentation } \\
\hline Regular multicoloured & $49(17.4)$ & $1(0.7)$ & $19(9.2)$ & $2(1.8)$ \\
\hline Regular uniform & $25(8.9)$ & $1(0.7)$ & $26(12.6)$ & $2(1.8)$ \\
\hline Irregular & $208(73.8)$ & $139(98.6)$ & $161(78.2)$ & $108(96.4)$ \\
\hline \multicolumn{5}{|l|}{ General pattern } \\
\hline Homogeneous & $91(32.3)$ & $33(23.4)$ & $31(15.0)$ & $6(5.4)$ \\
\hline Reticular & $163(57.8)$ & $66(46.8)$ & $38(18.4)$ & $1(0.9)$ \\
\hline Globular & $90(31.9)$ & $38(27.0)$ & $8(3.9)$ & $1(0.9)$ \\
\hline Non-specific & $12(4.3)$ & $36(25.5)$ & $117(56.8)$ & $98(87.5)$ \\
\hline \multicolumn{5}{|l|}{ Specific pattern } \\
\hline Dots/glob regular & $46(16.3)$ & $3(2.1)$ & $6(2.9)$ & 0 \\
\hline Dots/glob irregular & $76(27.0)$ & $68(48.2)$ & $15(7.3)$ & $11(9.8)$ \\
\hline Network regular & $76(27.0)$ & $2(1.4)$ & $23(11.2)$ & $1(0.9)$ \\
\hline Network irregular & $86(30.5)$ & $72(51.1)$ & $13(6.3)$ & $3(2.7)$ \\
\hline Network broadened & $25(8.9)$ & $24(17.0)$ & $4(1.9)$ & 0 \\
\hline Network negative & $14(5.0)$ & $21(14.9)$ & $10(0.5)$ & $4(3.6)$ \\
\hline Streaks irregular & $37(13.1)$ & $42(29.8)$ & $2(1.0)$ & $1(0.9)$ \\
\hline Grey-blue areas & $62(22.0)$ & $47(33.3)$ & $26(12.6)$ & $6(5.4)$ \\
\hline White areas & $10(3.5)$ & $18(12.8)$ & $6(2.9)$ & $8(7.1)$ \\
\hline Blue-white areas & $8(2.8)$ & $19(13.5)$ & $2(1.0)$ & $2(1.8)$ \\
\hline Peppering & $14(5.0)$ & $21(14.9)$ & $11(5.3)$ & $4(3.6)$ \\
\hline Blue-whitish veil & $21(7.4)$ & $30(21.3)$ & $11(5.3)$ & $3(2.7)$ \\
\hline Comedo-like openings & $4(1.4)$ & $1(0.7)$ & $27(13.1)$ & $4(3.6)$ \\
\hline Milia-like cysts & $8(2.8)$ & $6(4.3)$ & $36(17.5)$ & $5(4.5)$ \\
\hline Blue-grey ovoid nests & $2(0.7)$ & 0 & $4(1.9)$ & $29(25.9)$ \\
\hline Multiple blue-grey globules & $2(0.7)$ & 0 & 0 & $24(21.4)$ \\
\hline
\end{tabular}

Dermoscopic criteria had to be present in more than $10 \%$ of the lesions of at least one group to be listed.

post new cases if they wish. When a case is added to the archive, the information from the forum is aggregated, clarified and finalized by the site administrators, who are the only members who can add or delete data from the archive. Figure 3 demonstrates the procedure of selecting cases from the Internet discussion forum and adding them to the web-based dermoscopy image archive.

In contrast to dermoscopy atlases or web-based courses, discussion forums facilitate the presentation of numerous unusual lesions of interest, many of which demonstrate atypical dermoscopic features. The analysis of archived cases indicates that a high number of lesions with clashing dermoscopic features have been submitted for discussion by forum members. For example, quite a high percentage of benign archived lesions showed an irregular pigmentation and asymmetry, like the seborrhoeic keratosis shown in figure 1. Additionally, naevi, which were the most frequent lesions in our investigation, often showed irregular dots/globules, irregular network, blue-grey areas or irregular streaks and may have posed diagnostic and management problems to the authors. Interestingly, a quarter of the archived lesions were diagnosed in consensus between the discussants. This indicates that the diagnosis was obvious to them, in contrast to the author posting the case, and likely due to a higher level of clinical and/or dermoscopic experience.

Some lesions were not posted for advice on the diagnosis or management, but because the authors wanted to 


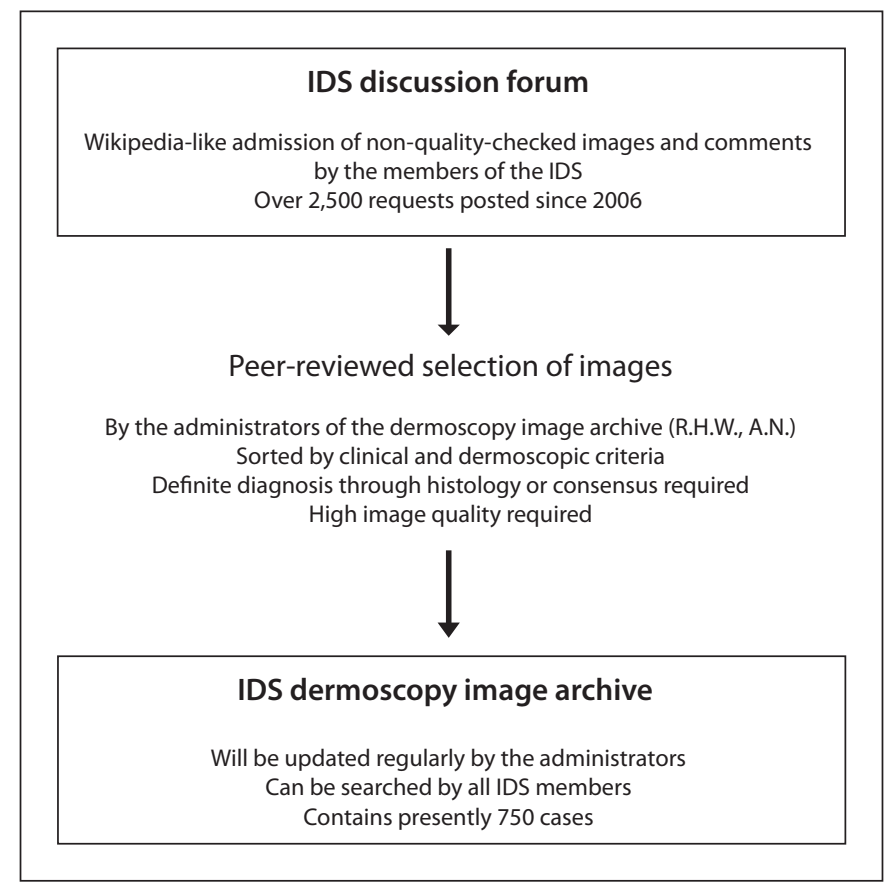

Fig. 3. Demonstration of the selection process of cases from the IDS discussion forum for the IDS dermoscopy image archive.

share them with the community to promote the knowledge of the clinical and dermoscopic appearance of rare lesions like Merkel cell carcinomas or tumours of the sweat glands.

It has previously been demonstrated [1] that open-access teledermatology may serve as a successful platform $[9,10]$ for challenging dermoscopic cases, where advice on diagnosis and therapy can be provided. This is emphasized by the fact that past studies have shown a high diagnostic concordance between telediagnosis and face-toface diagnosis for pigmented lesions [11-13]. The possibility of searching for a combination of dermoscopic and clinical features in the case archive is, to the best of our knowledge, unique and allows the image archive to serve as a form of encyclopaedia. Further studies would be necessary to determine the real impact of the image archive on the improvement of the users' dermoscopic skills.

\section{Acknowledgement}

\section{Authors}

Abimelec Philippe, Alendar Faruk, Alhazaa Mahlab, Alonso Carlos Esteban, Argenziano Giuseppe, Beck Hilton, Boitier Françoise, Bourne Peter, Bozzi Mario, Breuillard François, Bru Francisco, Bugatti Leonardo, Burns John, Cacuci Mirela, Campos Do
Carmo Gabriella, Canning Greg, Chan Gavin, Cook Benjamin, Cowell Lester, Cunliffe Timothy, Di Stefano Andrea Giuseppe, Díaz Ramón José Luis, Dreval Dmitry, Drljevic Irdina, Ehrsam Eric, Fernandez De Pierola Santiago, Fox Gary, Gabler Gerald, Gamo Reyes, Garcia Carlos, Giacomel Jason, Gómez Duaso Anselmo Javier, Gourhant Jean-Yves, Hannon Chris, HofmannWellenhof Rainer, Hopkins Keith, Ionescu Paul Ilarian, Johnson Karen, Jyothish George, Kelly Lester, Landi Christian, Levin Alan, Manasievska Emilia, Mansur Ayșe Tülin, Martínez Díaz De Argandoña Concepción, McCormack Iona, Michenko Anna, Muir James, Nachiappan Siva, Nair Padmaja, Negreanu Rodica, Pastar Zrinjka, Peace Julian, Pellizzari Gary, Perera C. Mervyn, Phillips Alison, Piérard Eric, Poleva Irina, Pudova Jekaterina, Rasnik Favotto Bernardina, Riley Martin, Rodriguez Saa Sonia, Roediger Marc, Ruffion Nadia, Schwartz Rodrigo, Scriven William, Silverstein Marc, Simionescu Olga, Sortino-Rachou Ana Maria, Soyer Peter H., Spagnol Abraham Leonardo, Stansbury John A., Stelios Minas, Stojanovic Gordana, Strydom Franz, Tanaka Masaru, Timar Mariana, Tvrdeich Geoff, Vargas-Diez Erich, Viorel Anton, Vlajkovic Slobodan, Weaver Jere, Willett Rodney, Yayl Sava, Zalaudek Iris.

\section{Discussants}

Aguilera Peiró Paula, Alvarez Cuesta Cesar, Aydingoz Ikbal, Blum Andreas, Bogush Ilya, Bojanic Petar, Bonifazi Ernesto, Callan Michael, Cantu Pedro, Chamberlain Alex, Cunliffe Timothy, Daud Yunus, Davis Marcia, Dixon Anthony, Durdu Murat, Ellis Graham, Filosa Giorgio, Fishburn Paul, Ghaninezhad Haydeh, Güçlüer Nacar Hülya, Hackett Timothy, Hadiuzzaman M.D., Helppikangas Hana, Hidalgo-Matlock Benjamin, Hosking Simon, Keir Jeffrey, Kendall Clare, Koutsioukis Konstantinos, Kowalczuk Alicia, Loriente Diego Martín, Martella Alessandro, Martini Mary, Massimo Guadagni, Mattio Roberto, McCoy Dan, McPhee Ewen, Merlano Cesar Augusto, Mizori Osmat, Piccolo Domenico, Pizarro Angel, Poleksic Predrag, Prokop David, Puig Susana, Pyne John, Rajpara Sanjay, Riseley Judith, Rosendahl Cliff, Sadigh Ershadi Valeria, Said Marco Maier, Salerni Gabriel, Saltzer Geoff, Sawdon David, Scanni Gaetano, Shah Syed N., Silverstein Marc, Toliusis Vytautas, Topovsek Chris, Tschandl Philipp, Tzalokostas Vasilios, Velkov Valentin, Wassall Stephen.

\section{Disclosure Statement}

G. Gabler, H.P. Soyer and R. Hofmann-Wellenhof are shareholders of e-derm-consult Gmbh, Graz, Austria.

References

1 Soyer HP, Hofmann-Wellenhof R, Massone C, Gabler G, Dong H, Ozdemir F, Argenziano G: Telederm.org: freely available online consultations in dermatology. PLoS Med 2005;2:e87.

2 Massone C, Wurm EM, Hofmann-Wellenhof R, Soyer HP: Teledermatology: an update. Semin Cutan Med Surg 2008;27:101105. 
3 Ian McColl: Skin Cancer College of Australia and New Zealand. Skin cancer blog. 2004. http://www.sccanz.com.au/skin-cancerblog (accessed August 9, 2010).

4 Eric Ehrsam: Dermoscopy. 2007. http://dermoscopic.blogspot.com (accessed August 9, 2010).

5 Abidi SS, Hussini S, Sriraj W, Thienthong S, Finley GA: Knowledge sharing for pediatric pain management via a Web 2.0 framework. Stud Health Technol Inform 2009;150:287291.

-6 Im EO, Lee SH, Liu Y, Lim HJ, Guevara E, Chee W: A national online forum on ethnic differences in cancer pain experience. Nurs Res 2009;58:86-94.
7 Im EO, Lee B, Chee W, Dormire S, Brown A: A national multiethnic online forum study on menopausal symptom experience. Nurs Res 2010;59:26-33.

8 Malvehy J, Puig S, Argenziano G, Marghoob AA, Soyer HP, International Dermoscopy Society Board members: Dermoscopy report: proposal for standardization. Results of a consensus meeting of the International Dermoscopy Society. J Am Acad Dermatol 2007;57:84-95.

-9 Massone C, Soyer HP, Hofmann-Wellenhof R, Di Stefani A, Lozzi GP, Gabler G, Dong H, Argenziano G, Ozdemir F, Fink-Puches R, Salmhofer W, Zalaudek I, Nunzi E, Kerl H: Two years' experience with Web-based teleconsulting in dermatology. J Telemed Telecare 2006; 12:83-87.

10 Huntley AC, Smith JG: New communication between dermatologists in the age of the Internet. Semin Cutan Med Surg 2002:21:202204.
1 Piccolo D, Smolle J, Wolf IH, Peris K, Hofmann-Wellenhof R, Dell'Eva G, Burroni M, Chimenti S, Kerl H, Soyer HP: Face-to-face diagnosis vs telediagnosis of pigmented skin tumors: a teledermoscopic study. Arch Dermatol 1999;135:1467-1471.

12 Piccolo D, Peris K, Chimenti S, Argenziano G, Soyer HP: Jumping into the future using teledermoscopy. Skinmed 2002;1:20-24.

13 Piccolo D, Smolle J, Argenziano G, Wolf IH, Braun R, Cerroni L, Ferrari A, HofmannWellenhof R, Kenet RO, Magrini F, Mazzocchetti G, Pizzichetta MA, Schaeppi H, Stolz W, Tanaka M, Kerl H, Chimenti S, Soyer HP: Teledermoscopy - results of a multicentre study on 43 pigmented skin lesions. J Telemed Telecare 2000;6:132-137. 